\title{
A method to modify the response of neutron dosimeters in the fields with energy spectra different from the calibration field
}

\author{
A. Moslehi ${ }^{*}$, S. Baradaran ${ }^{2,3}$, P. Rezaeian ${ }^{1}$
}

\begin{abstract}
AFFILIATION
${ }^{1}$ Radiation Applications Research School, Nuclear Science and Technology Research Institute, AEOI, Tehran, Iran ${ }^{2}$ Reactor and Nuclear Safety Research School, Nuclear Science and Technology Research Institute, AEOI, Tehran, Iran ${ }^{3}$ Iranian Nuclear Regulatory Authority, National Radiation Protection Department, AEOI, Tehran, Iran
\end{abstract}

Author to whom correspondence should be addressed: ammoslehi@aeoi.org.ir

\begin{abstract}
One problem in neutron dosimetry is that dosimeter responses per unit dose-equivalent in measurement and calibration fields are different. Hence, the neutron dose suffers a large uncertainty. In this work, a correction method is introduced to modify the dosimeters response in the fields with known energy spectra. To examine it, responses of thermoluminescence dosimeters (TLDs) to fast neutrons in ${ }^{241} \mathrm{Am}$-Be (calibration), ${ }^{252} \mathrm{Cf}$ and ${ }^{239} \mathrm{Pu}$-Be fields for four personal dose-equivalents $\left(\mathrm{H}_{\mathrm{p}}(10)\right.$ values) of $5,10,15$ and $20 \mathrm{mSv}$ are measured. The results obtained reveal that the maximum differences of the original responses measured in ${ }^{252} \mathrm{Cf}$ and ${ }^{239} \mathrm{Pu}$-Be fields from ${ }^{241} \mathrm{Am}$-Be field are $15 \%$ and $42 \%$, respectively. After correction, above differences reduce to $4.7 \%$ and $10.8 \%$. Finally, it can be concluded that the method proposed here, improves the accuracy of dose measurement in the neutron fields with known energy spectra.
\end{abstract}

Keywords: Fast neutron spectrum; Response; Calibration field; Correction factor; TLD

\section{INTRODUCTION}

Through the past few decades ionizing radiations have been increasingly used in medicine, biology and industry. They have been applied for various applications such as producing radiopharmaceuticals, cancer therapy, sterilization or processing products, analyzing samples, scientific researches, etc. [1-4]. Thus, methods and devices appropriate for accurate evaluation of radiation dose has been a major topic in radiation protection in order to avoid or at least reduce the hazards of radiation for personnel working in nuclear facilities and also people in the society [5]. Neutron dosimetry is the most challenging one compared with the other ionizing radiations. Neutrons produce various charged particles when interact with matter and their interaction cross-sections are highly energy-dependent. In addition, neutrons emitted from the radio-isotopic or acceleratorbased sources possess energy spectrum and are mostly mixed with gamma rays [6]. On the other hand, there are no sources emitting mono-energetic neutrons for calibration procedure. Usually, the 
two well-known sources in this case are ${ }^{241} \mathrm{Am}-\mathrm{Be}$ and ${ }^{252} \mathrm{Cf}$. Their energy spectra extend from low energies to about $12 \mathrm{MeV}$ [7]. A problem occurs when the dosimeters are calibrated in these fields and then are used for dosimetry in the unknown fields or those with different energy spectra (measurement fields). It can be observed that response of a typical neutron dosimeter per unit of dose-equivalent (rate) in a measurement field differs from that in the calibration field. Consequently, there will be some large uncertainty in the dose estimated by the dosimeters which originates from the strong dependence of dosimeters response on the neutron energy.

This dependency has been a subject of interest in many investigations. For example, in 1992, Rimpler compared the dose-equivalent response of a few neutron survey meters in ${ }^{252} \mathrm{Cf}$ and ${ }^{239} \mathrm{Pu}-\mathrm{Be}$ fields. He found large variations in the responses regarding the uncertainty criteria expected in routine monitoring [8]. In 1995, Chartier el al, expressed that to fulfill the recommendations given in ICRP publication 60, substantial improvements to the characteristics of neutron dosimeters were necessary. Their work dealt with the calibration procedures in the frame of realistic neutron spectra in order to enhance the accuracy of neutron dosimetry [9]. In 2002, Tanner et al, investigated the effect of energy dependence of the response of neutron personal dosimeters routinely used in the UK on accuracy of dose estimation [10]. They concluded that due to inherent problems associated with the energy response of neutron dosimeters studied; probable systematic error occurs in the dose measurement. Further, in 2018 the uncertainty of personal neutron dosimeters at various neutron fields was studied by Pyshkina et al [11]. They examined an albedo TLD dosimeter and a direct-reading personal neutron dosimeter and observed that ratio of dosimeters reading and personal dose-equivalent for a variety of workplace neutron spectra after calibration varied greatly in a range from 0.6 to 106 .
On the other hand, there are few works in which efforts are done to solve the above problem. In 2006, Raisali et al, analyzed the streaming of neutrons and gamma rays in the maze of thallium production target room [12]. Since they faced an unknown neutron energy spectrum in the maze, they calculated dose-equivalent rate of neutrons by MCNP code as the true dose value. It was found different from the values measured by a $\mathrm{BF}_{3}$ proportional counter calibrated in ${ }^{252} \mathrm{Cf}$ field. Therefore, they suggested a correction factor to be applied to the dose-equivalent rates measured by the counter.

Although large amount of uncertainty is acceptable in routine personal dosimetry, achieving less uncertainties in dose measurements especially in neutron fields is of interest. In the present work, an analytical method is proposed to modify the response of a typical neutron dosimeter in the fields with known energy spectra other than the calibration field. The final goal is to reduce the uncertainty of dose measurement.

\section{THEORY}

Let's consider a typical neutron dosimeter with response $R$ corresponding to dose-equivalent (rate) $H$ in the calibration field relating to each other by Eq. (1):

$$
H=R \times k
$$

in which $k$ is the calibration factor to convert the response (considered as the true response) to the dose-equivalent. Likewise, when this dosimeter is used in a neutron field different from the calibration field (e.g., workplace), we have:

$$
H^{\prime}=R^{\prime} \times k
$$

where $R^{\prime}$ is the response and $H^{\prime}$ the dose-equivalent estimated by the dosimeter. In general, it is observed that per unit dose-equivalent responses in the two fields are not the same, i.e., $R^{\prime} \neq R$. As a 
result, after applying the calibration factor, doseequivalent measured in the workplace is different from the true value. Therefore, a correction factor, $c$, has to be used to modify the dosimeter response to obtain the true dose, as given by Eq. (3):

$$
H \approx R^{\prime} \times c \times k
$$

Because of the response dependency on the neutron energy, $c$ must consider the weighting factors of different single-energies included in the energy spectra of the calibration and measurement fields. The other requirement is the dosimeter response to these single-energies. Therefore, the correction factor can be written as Eq. (4):

$$
c=\frac{\sum_{i} \frac{R}{R_{i}}\left(\frac{f_{i}}{f_{i}^{\prime}}\right)}{\sum_{i}\left(\frac{f_{i}}{f_{i}^{\prime \prime}}\right)}
$$

with $R$ as the response in the calibration field given by Eq. (1), $R_{i}$ the response to "i"th single-energy, $f_{i}$ and $f^{\prime}{ }_{i}$ the weighting factors of "i"th energy in the energy spectra of the calibration and measurement fields, respectively. The summation is also taken over the single-energies included in the energy spectra.

\section{MATERIALS AND METHOD}

Since TLDs are widely used for ambient and individual dosimetry [5], the theory described above was examined on TLD responses in three different fast neutron fields with known energy spectra. First, the original responses were measured. Then, the correction factor $c$ as well as modified responses was determined.

For measuring the response to fast neutrons, a TLD card (from Harshaw Company) inside a proper badge was used. A schematic view of the TLD card is shown in Fig. 1. Numbers 1 to 4 denoted the TLD chips named as $\mathrm{TL}_{1}$ to $\mathrm{TL}_{4}$. $\mathrm{TL}_{1}$ and $\mathrm{TL}_{4}$ were $T L D-600$ while $\mathrm{TL}_{2}$ and $\mathrm{TL}_{3}$ were TLD-700. A cadmium filter with $0.7 \mathrm{~mm}$ thickness was placed behind the lower half of the card. Since TLD-600 was sensitive to both neutrons and gamma rays, TLD-700 was utilized to separate dose fraction of gamma rays from neutrons. The card was placed on an ISO slab phantom with a dimension $30 \mathrm{~cm} \times 30 \mathrm{~cm} \times 15 \mathrm{~cm}$ made of Perspex (PMMA) walls filled with water. Functions of different TLDs are summarized as follows:

$\mathrm{TL}_{1}$ determined dose of thermal neutrons (emitted from the source, if there is any), albedo neutrons (fast neutrons backscattered in the phantom and became thermal) and gamma rays. $\mathrm{TL}_{2}$ and $\mathrm{TL}_{3}$ determined dose of gamma rays and $\mathrm{TL}_{4}$ specified dose of thermal neutrons and gamma rays.

Standard sources of ${ }^{241} \mathrm{Am}-\mathrm{Be},{ }^{252} \mathrm{Cf}$ and ${ }^{239} \mathrm{Pu}-$ Be existing in Atomic Energy Organization of Iran (AEOI) with known dose-equivalent rates were chosen as the desired neutrons fields. The energy spectra of these fields were known [13,14]. Figure 2 depicts the normalized energy spectra of these neutron sources. Characteristics of the three sources at the time of measurements are listed in Table 1. The distance between the card and each source was set to be $1 \mathrm{~m}$. Also, ${ }^{241} \mathrm{Am}$-Be source was considered as the calibration field.

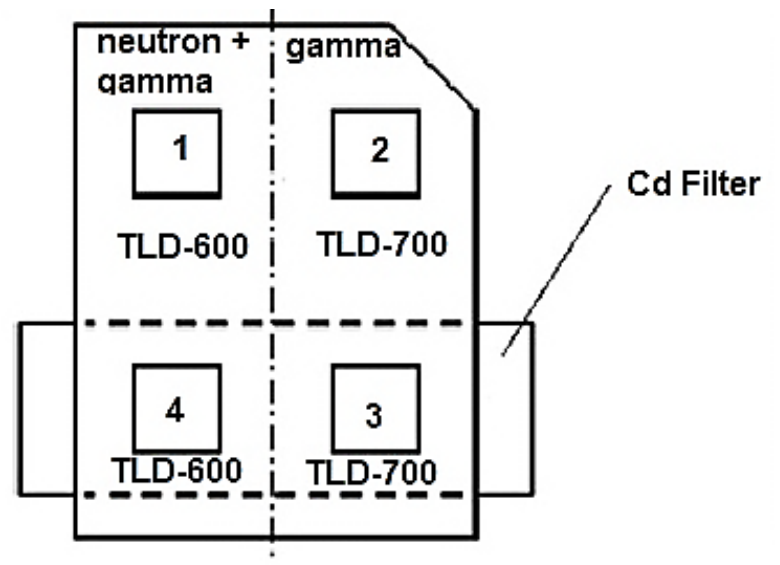

Fig. 1. Schematic view of the TLD card used for measuring the response to fast neutrons. The numbers 1 to 4 refer to TLD-600, TLD-700, TLD 700 and TLD600 , respectively. 


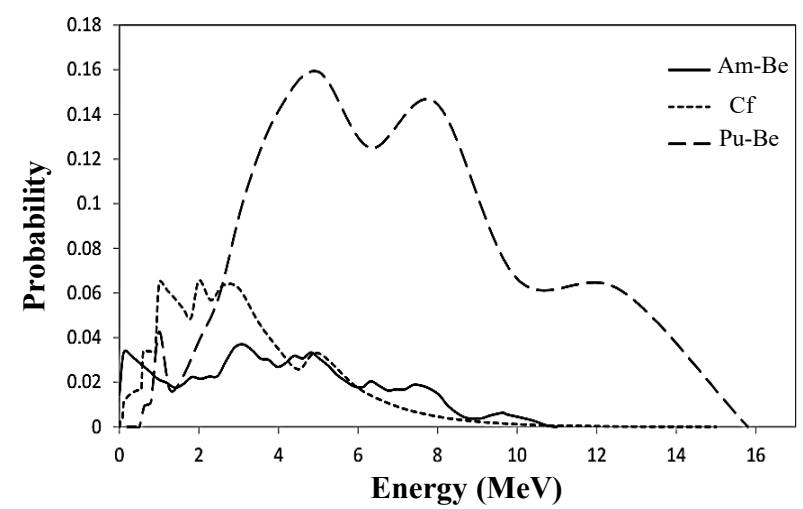

Fig. 2. Normalized energy spectra of the three neutrons sources used in this work $[13,14]$.

\section{Table 1}

Characteristics of Three Neutron Sources in AEOI

\begin{tabular}{cccc}
\hline Source & $\begin{array}{c}\text { Activity } \\
(\mathrm{Ci})\end{array}$ & $\begin{array}{c}\text { Emission rate } \\
\left(\mathrm{n} \mathrm{s}^{-1}\right)\end{array}$ & $\begin{array}{c}\text { Neutron dose-equivalent } \\
\text { rate at } 1 \mathrm{~m}^{\left(\mu \mathrm{Sv} \mathrm{h}^{-1}\right)}\end{array}$ \\
\hline${ }^{241} \mathrm{Am}-\mathrm{Be}$ & 9.65 & $1.97 \times 10^{7}$ & 228 \\
${ }^{252} \mathrm{Cf}$ & 2.2 & $2.28 \times 10^{7}$ & 146 \\
${ }^{239} \mathrm{Pu}-\mathrm{Be}$ & 2.5 & $1.66 \times 10^{7}$ & 198 \\
\hline
\end{tabular}

In separate irradiations in each field, the time was set such that the personal dose-equivalents $\left(\mathrm{H}_{\mathrm{p}}(10)\right.$ values) at the position of the card become 5, 10, 15 and $20 \mathrm{mSv}$. Before and after irradiation, the TLDs were read by a TLD reader (Harshaw model 6600) and their net response in terms of $\mathrm{nC}$ were determined. For any dose-equivalent, five measurements were carried out. The mean value of the five net responses was considered as the desired response corresponding to any dose-equivalent. Eventually, the response to fast neutrons was obtained by the contribution of albedo neutrons and subtracting the contribution of gamma rays using $T L_{2}$ and $T L_{3}$ as given in Eq. (5):
$R=\left(T L_{1}-T L_{4}\right)-0.34 T L_{4}$

in which $T L_{1}$ and $T L_{4}$ were the response of first and forth TLDs. The term $0.34 T L_{4}$ originated from the correction of the leakage of thermal neutrons from the cadmium filter in the card [15]. One point to be considered here is that in low dose rates TLD-700 is not sensitive to neutrons, while in high dose rate fields such as research reactors, it may respond to neutrons leading to overestimation of the gamma ray dose [16].

Total uncertainty of $R$ was $20 \%$ with $95 \%$ confidence level obtained by considering all possible contributions included in the dosimetry system (e.g., number of readings, fading, homogeneity, etc.) regarding GSR part 3 and GSG7 standard documents of International Atomic Energy Agency (IAEA) [17, 18].

\section{RESULT AND DISCUSSION}

In this part, first the original responses of TLDs in the neutron fields considered are compared and discussed. Then, the correction factors for the ${ }^{252} \mathrm{Cf}$ and ${ }^{239} \mathrm{Pu}-\mathrm{Be}$ fields are found and the corrected responses are compared with the original data.

\section{A. Original Responses}

Figure 2 shows variation of the response (in the unit of $\mathrm{nC}$ ) versus dose-equivalent in ${ }^{241} \mathrm{Am}-\mathrm{Be}$, ${ }^{252} \mathrm{Cf}$ and ${ }^{239} \mathrm{Pu}-\mathrm{Be}$ fields. Error bars specify the uncertainty with $95 \%$ confidence level. To clarify the differences between the responses with more details, the data in Fig. 3 are listed in Table 2.

Table 2

Original TLD Responses (nC) to Fast Neutrons of ${ }^{241} \mathrm{Am}-\mathrm{Be},{ }^{252} \mathrm{Cf}$ and ${ }^{239} \mathrm{Pu}$-Be Fields for Four Dose-equivalents. The Differences from the Responses in ${ }^{241} \mathrm{Am}$-Be Field are Given

\begin{tabular}{cccccc}
\hline $\mathrm{H}(\mathrm{mSv})$ & ${ }^{241} \mathrm{Am}-\mathrm{Be}$ & ${ }^{252} \mathrm{Cf}$ & Diff. (\%) & ${ }^{239} \mathrm{Pu}-\mathrm{Be}$ & Diff. (\%) \\
\hline 5 & $51.98 \pm 10.40$ & $41.12 \pm 8.22$ & 13.14 & $29.90 \pm 5.98$ & 42.50 \\
10 & $111.64 \pm 22.23$ & $94.98 \pm 19.00$ & 14.92 & $67.15 \pm 13.43$ & 39.85 \\
15 & $138.80 \pm 27.76$ & $123.37 \pm 24.67$ & 11.12 & $95.62 \pm 21.79$ & 31.11 \\
20 & $200.16 \pm 40.03$ & $171.58 \pm 34.32$ & 14.28 & $131.76 \pm 26.37$ & 34.12 \\
\hline
\end{tabular}




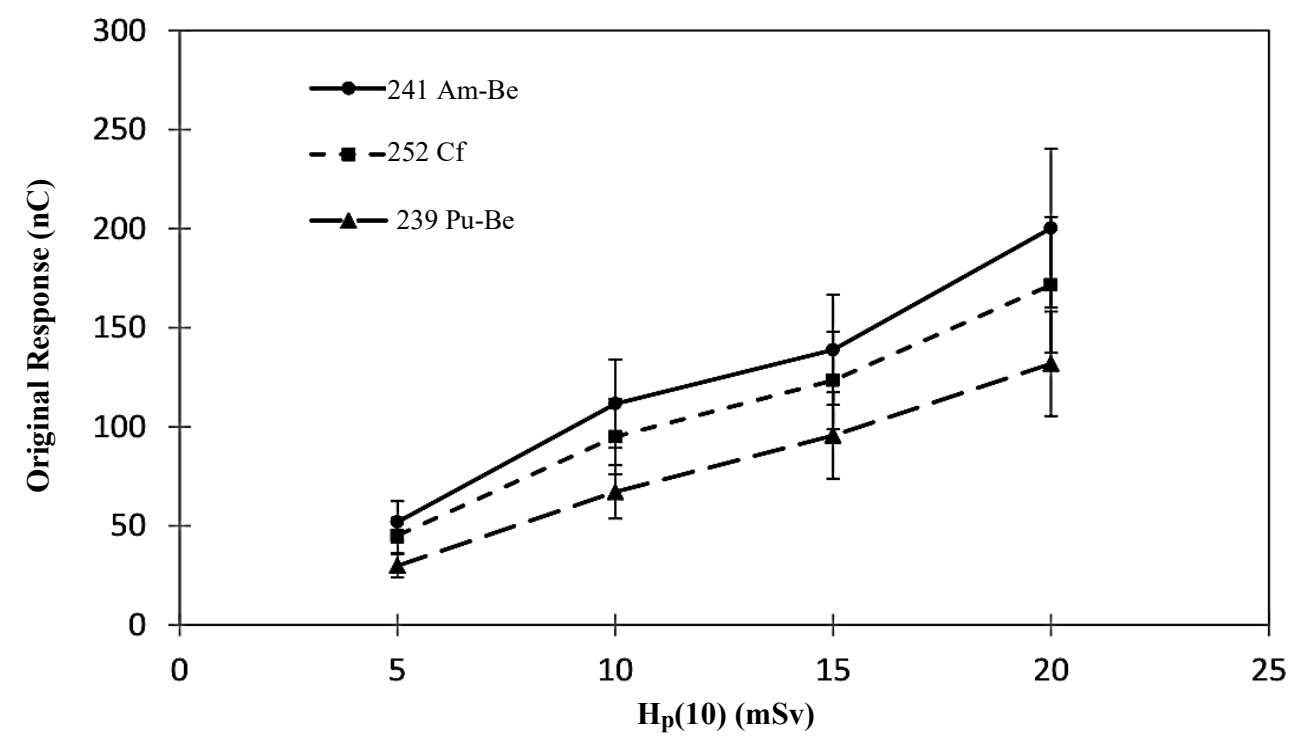

Fig. 3. Original TLD responses to fast neutrons vs. dose-equivalents in the three different fields. Error bars show the uncertainty with $95 \%$ confidence level.

As can be observed, for a given doseequivalent, the responses in ${ }^{252} \mathrm{Cf}$ and ${ }^{239} \mathrm{Pu}-\mathrm{Be}$ fields are smaller than that in ${ }^{241} \mathrm{Am}-\mathrm{Be}$ field. Maximum discrepancies $14.9 \%$ at $10 \mathrm{mSv}$ and $42.5 \%$ at $5 \mathrm{mSv}$ for ${ }^{252} \mathrm{Cf}$ and ${ }^{239} \mathrm{Pu}-\mathrm{Be}$ are observed, respectively. Part of these differences refers to the response uncertainty which is acceptable and the rest is related to the dependence of interactions and cross-sections on the neutron energy. When the energy spectra and the weighting factors of single-energies are different, contribution of a specific interaction leading to an observable effect in the dosimeter and its response will be different too.

\section{B. Single-energy Responses}

According to Eq. (4) besides the response to the calibration field, one needs the response to singleenergies for the correction method. From the fact that in the case of TLDs, these responses cannot directly be measured by the TLD reader, they can be found from the response in the calibration field (here, ${ }^{241} \mathrm{Am}-\mathrm{Be}$ ) as described below:

The charge measured by the reader is proportional to the absrbed dose in the TLD (the proportionality constant is fixed only when a reader is used for all TLDs). From Table 2 it is known that the response to fast neutrons of ${ }^{241} \mathrm{Am}-\mathrm{Be}$ for 5 $\mathrm{mSv}$ is $51.98 \mathrm{nC}$. Also, the mean quality factor for these neutrons is 12.6 [18]. According to the relation $H=\bar{Q} D$, in which $\bar{Q}$ is the mean quality factor and $D$ is the absorbed dose, one has $D=3.97$ $\times 10^{4} \mathrm{~Gy}$ for ${ }^{241} \mathrm{Am}-\mathrm{Be}$ neutrons. Assuming that the dose-equivalent for the single-energies are the same as that for the energy spectrum of ${ }^{241} \mathrm{Am}-\mathrm{Be}$ neutrons, the absorbed doses corresponding to the single-energies are derived by applying their mean quality factors [19]. Finally, the response to any single-energy can be found by Eq. (6):

$R_{i}=\frac{D_{i}}{D} R$

in which $R_{i}$ is the responses to "i"th single-energy, $R$ is the response to ${ }^{241} \mathrm{Am}-\mathrm{Be}$ field, $D_{i}$ is the absorbed dose corresponding to " $i$ "th single-energy and $D$ is the absorbed dose associated with ${ }^{241} \mathrm{Am}$ Be field. Likewise, the responses for the other dose-equivalents are calculated.

Values of the mean quality factors and the response (vs. nC) to single-energies for different dose-equivalents are listed in Table 3. Moreover, the responses for different dose-equivalents are plotted in Fig. 4. 


\section{Table 3}

Values of the Mean Quality Factor and Response (vs. $n C)$ to Single-energies for Different Dose-equivalent values

\begin{tabular}{cccccc}
\hline $\begin{array}{c}\text { Energy } \\
(\mathrm{MeV})\end{array}$ & $\bar{Q}[19]$ & $\begin{array}{c}5 \\
\mathrm{mSv}\end{array}$ & $\begin{array}{c}10 \\
\mathrm{mSv}\end{array}$ & $\begin{array}{c}15 \\
\mathrm{mSv}\end{array}$ & $\begin{array}{c}20 \\
\mathrm{mSv}\end{array}$ \\
\hline 0.1 & 17.7 & 36.98 & 73.96 & 110.94 & 147.92 \\
0.2 & 22.0 & 29.78 & 59.56 & 89.34 & 119.12 \\
0.5 & 23.5 & 27.88 & 55.76 & 83.64 & 111.52 \\
0.7 & 23.1 & 28.20 & 56.40 & 84.60 & 112.80 \\
1 & 23.0 & 28.48 & 56.96 & 85.44 & 113.92 \\
2 & 18.1 & 36.16 & 72.32 & 108.48 & 144.64 \\
3 & 14.0 & 46.78 & 93.56 & 140.34 & 187.12 \\
4 & 12.9 & 50.75 & 101.50 & 152.25 & 203.00 \\
5 & 11.0 & 59.54 & 119.08 & 178.62 & 238.16 \\
6 & 10.0 & 65.50 & 131.00 & 196.50 & 262.00 \\
7 & 9.0 & 72.78 & 145.56 & 218.34 & 291.12 \\
8 & 8.5 & 77.05 & 154.10 & 231.15 & 308.20 \\
9 & 8.0 & 81.87 & 163.74 & 245.61 & 327.48 \\
10 & 8.5 & 77.01 & 154.02 & 231.03 & 308.04 \\
11 & 7.5 & 87.34 & 174.68 & 262.02 & 349.36 \\
\hline 14 & 7.6 & 86.18 & 172.36 & 258.54 & 344.72 \\
\hline & & & & & \\
\hline
\end{tabular}

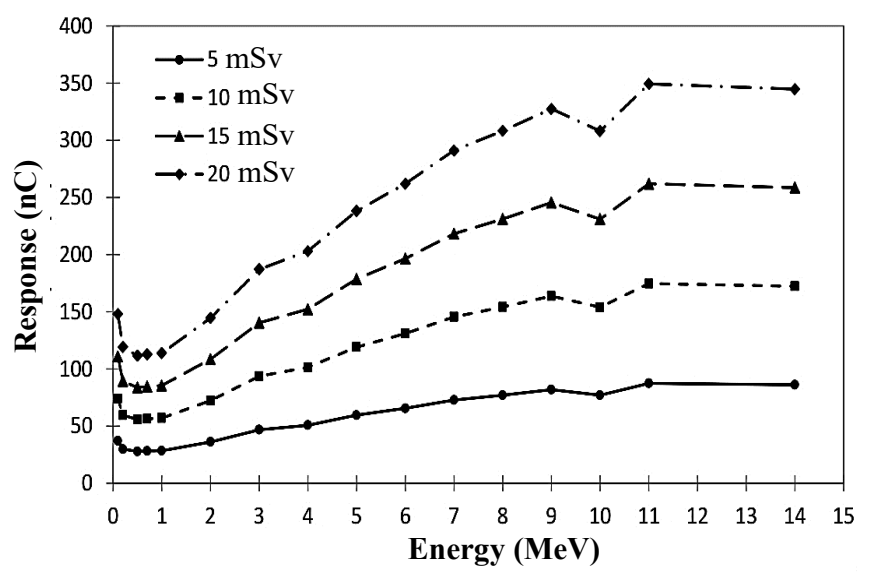

Fig. 4. TLD responses to single-energies for different dose-equivalents considered in this paper

\section{Corrected responses}

After determining the response to single-energies, the total correction factors for ${ }^{252} \mathrm{Cf}$ and ${ }^{239} \mathrm{Pu}-\mathrm{Be}$ fields are determined by Eq. (4) and the weighting factors of single-energies derived from the energy spectra [13,14]. In Table 4, values of $c$ corresponding to different dose-equivalents and their mean value are presented. The mean correction factors are obtained equal to 1.12 and 1.55 for ${ }^{252} \mathrm{Cf}$ and ${ }^{239} \mathrm{Pu}$-Be fields respectively. Clearly, the bigger difference found between the original responses, the larger correction factor needed to modify the responses.

The modified responses calculated by Eq. (4) are plotted in Fig. 5. Also, Table 5 compares them with those in ${ }^{241} \mathrm{Am}-\mathrm{Be}$ field. Clearly, the maximum difference from the responses in ${ }^{241} \mathrm{Am}$ Be field has reduced to $4.7 \%$ and $10.8 \%$ for ${ }^{252} \mathrm{Cf}$ and ${ }^{239} \mathrm{Pu}-\mathrm{Be}$, respectively $(68 \%$ and $74 \%$ reduction compared with the original data) leading to a better agreement between the responses.

Table 4.

Total Correction Factors for ${ }^{252} \mathrm{Cf}$ and ${ }^{239} \mathrm{Pu}$-Be Fields in Different Dose-equivalents and their Mean Values

\begin{tabular}{cccccc}
\hline Field & $\begin{array}{c}5 \\
\mathrm{mSv}\end{array}$ & $\begin{array}{c}10 \\
\mathrm{mSv}\end{array}$ & $\begin{array}{c}15 \\
\mathrm{mSv}\end{array}$ & $\begin{array}{c}20 \\
\mathrm{mSv}\end{array}$ & $\begin{array}{c}\text { Mean } \\
\text { correction } \\
\text { factor }\end{array}$ \\
\hline${ }^{252} \mathrm{Cf}$ & 1.14 & 1.22 & 1.01 & 1.10 & 1.12 \\
${ }^{239} \mathrm{Pu}-\mathrm{Be}$ & 1.58 & 1.70 & 1.41 & 1.52 & 1.55 \\
\hline
\end{tabular}

Fig. 5. Corrected responses of TLD to fast neutrons vs. dose-equivalents in three different fields

Note: The error bars show the uncertainty with $95 \%$ confidence level.

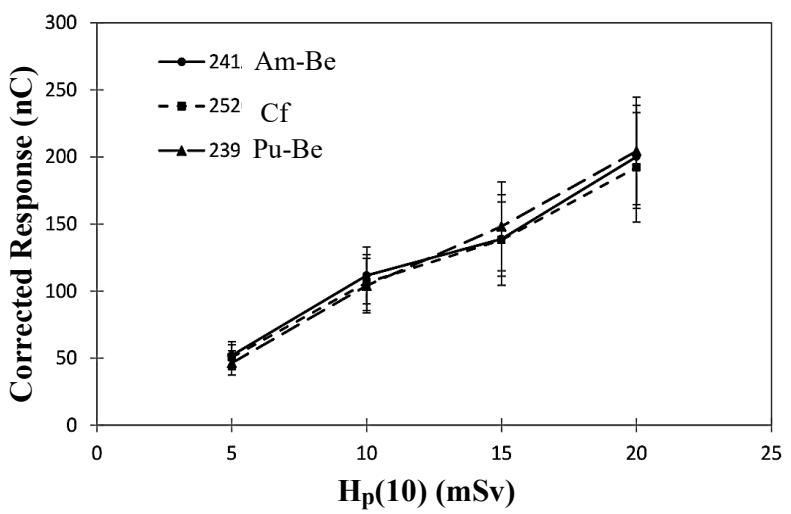




\section{Table 5}

Corrected Responses ( $n C$ ) to Fast $\mathrm{N}$ eutrons of ${ }^{252} \mathrm{Cf}$ and ${ }^{239} \mathrm{Pu}$-Be Fields for Different Dose equivalents Compared with the Responses in ${ }^{241} \mathrm{Am}$-Be Field

\begin{tabular}{cccccc}
\hline $\mathrm{H}(\mathrm{mSv})$ & ${ }^{241} \mathrm{Am}-\mathrm{Be}$ & ${ }^{252} \mathrm{Cf}$ & Diff. (\%) & ${ }^{239} \mathrm{Pu}-\mathrm{Be}$ & Diff. (\%) \\
\hline 5 & $51.98 \pm 10.40$ & $50.57 \pm 10.11$ & 2.72 & $46.35 \pm 9.27$ & 10.84 \\
10 & $111.64 \pm 22.23$ & $106.38 \pm 21.28$ & 4.71 & $104.08 \pm 20.82$ & 6.77 \\
15 & $138.80 \pm 27.76$ & $138.17 \pm 27.63$ & 0.45 & $148.21 \pm 29.42$ & 6.78 \\
20 & $200.16 \pm 40.03$ & $192.17 \pm 38.43$ & 3.99 & $204.38 \pm 40.87$ & 2.11 \\
\hline
\end{tabular}

\section{CONCLUSION}

In this paper a correction factor is introduced to modify the response of neutron dosimeters in the fields with energy spectra different from the calibration field. It includes the response in the calibration field relative to those of single-energies along with the weighting factors of these energies in the neutron energy spectra. This correction factor is examined on the responses of TLDs exposed to fast neutrons by experimental measurements in ${ }^{241} \mathrm{Am}$-be (calibration), ${ }^{252} \mathrm{Cf}$ and ${ }^{239} \mathrm{Pu}$-Be fields in the dose-equivalent range between $5 \mathrm{mSv}$ and $20 \mathrm{mSv}$. The results reveal that the maximum difference of the original responses corresponding to equal dose-equivalents in this range in ${ }^{252} \mathrm{Cf}$ and ${ }^{239} \mathrm{Pu}-\mathrm{Be}$ fields from that in ${ }^{241} \mathrm{Am}$-be field is $14.3 \%$ and $42.5 \%$ respectively. The correction method which is independent on the dose-equivalent value in the range studied, has reduced these discrepancies to $4.7 \%$ and $10.8 \%$. Therefore, it can be expected that by modifying the dosimeters response using this method, the accuracy of dose measurement in the neutron fields with known energy spectra will increase.

\section{ACKNOWLEDGMENTS}

The authors would like to thank G. Raisali for his valuable comments.

\section{REFERENCES}

1. R. J. Woods, A. K. Pikaev, Applied radiation chemistry: radiation processing, John Wiley \& Sons, (1993)

2. K. Schwochau, Technetium: chemistry and radiopharmaceutical applications, $2^{\text {nd }}$ Edition John Wiley \& Sons, New York, (2008)

3. F. M. Khan, J. P. Gibbons, The physics of radiation therapy, $5^{\text {th }}$ Edition, Lippincott Williams \& Wilkins, United State, (2014)

4. G. Jacobs, Radiation sterilization of pharmaceuticals: A review, Radiat. Phys. Chem. 26, 133 (1985)

5. G. Shani, Radiation dosimetry instrumentation and methods, $2^{\text {nd }}$ Edition, CRC press, United State, (2000)

6. International Commission on Radiation Units and Measurements. (1977), Neutron dosimetry for biology and medicine, Report No. 26, United State.

7. G. F. Knoll, Radiation detection and measurement, $4^{\text {th }}$ Edition, John Wiley \& Sons, New York, (2010)

8. A. Rimpler, Dose equivalent response of neutron survey meters for several neutron fields, Radiat. Prot. Dosim. 44, 189 (1992).

9. J. Chartier et al. Progress on calibration procedures with realistic neutron spectra, Radiat. Prot. Dosim. 57, 61 (1995).

10. R. Tanner et al. Effect of the energy dependence of response of neutron personal dosemeters routinely used in the UK on the accuracy of dose estimation, National Radiological Protection Board Didcot, UK, (2002). 
11. M. Pyshkina, M. Zhukovsky and A. Ekidin, in: Radiation Protection Dosimetry Conference, RAD Conference Proceedings 3, North Macedonia, June (2018) 36-41.

12. G. Raisali et al. Analysis of neutron and gammaray streaming along the maze of NRCAM thallium production target room, Appl. Radiat. Isotopes. 64, 940 (2006).

13. H. Ing and S. Makra, Compendium on neutron spectra in criticality accident dosimetry International Atomic Energy Agency, Austria, (1978).

14. R. Griffith, J. Palfalvi and U. Madhvanath, Compendium of neutron spectra and detector responses for radiation protection purposes International Atomic Energy Agency, Austria, (1990).
15. F. Torkzadeh and M. Taheri, Improvement and calibration of a SSNT personal dosemeter and study of importance of albedo factor for dose calculation, Radiat. Prot. Dosim. 125, 224 (2006).

16. A. C. Tássio, et al., Difference in TLD 600 and TLD 700 glow curves derived from district mixed gamma/neutron field irradiations, International Nuclear Atlantic Conference -INAC (2013).

17. International Atomic Energy Agency, International basic safety standards. (2014). Safety standard, Radiation protection and safety of radiation sources, Report No. GSR part 3, Austria.

18. International Atomic Energy Agency. (2018). Safety standard, Occupational radiation protection, Report No. GSG-7m, Austria.

19. International Commission on Radiation Units and Measurements. (1986). The quality factor in radiation protection, Report NO. 40, United State,

\section{How to cite this article}

Moslehi. A., Baradaran. S, Rezaeian. P, A method to modify the response of neutron dosimeters in the fields with energy spectra different from the calibration field, Nuclear Engineering Progress 1 (1): 1-8 (2021), DOI: 10.24200/nep.2021.1000 